\title{
Do treatment-induced changes in arterial stiffness affect left ventricular structure? A meta-analysis
}

Citation for published version (APA):

van der Waaij, K. M., Heusinkveld, M. H. G., Delhaas, T., Kroon, A. A., \& Reesink, K. D. (2019). Do treatment-induced changes in arterial stiffness affect left ventricular structure? A meta-analysis. Journal of Hypertension, 37(2), 253-263. https://doi.org/10.1097/HJH.0000000000001918

Document status and date:

Published: 01/02/2019

DOI:

10.1097/HJH.0000000000001918

Document Version:

Publisher's PDF, also known as Version of record

Document license:

Taverne

Please check the document version of this publication:

- A submitted manuscript is the version of the article upon submission and before peer-review. There can be important differences between the submitted version and the official published version of record.

People interested in the research are advised to contact the author for the final version of the publication, or visit the DOI to the publisher's website.

- The final author version and the galley proof are versions of the publication after peer review.

- The final published version features the final layout of the paper including the volume, issue and page numbers.

Link to publication

\footnotetext{
General rights rights.

- You may freely distribute the URL identifying the publication in the public portal. please follow below link for the End User Agreement:

www.umlib.nl/taverne-license

Take down policy

If you believe that this document breaches copyright please contact us at:

repository@maastrichtuniversity.nl

providing details and we will investigate your claim.
}

Copyright and moral rights for the publications made accessible in the public portal are retained by the authors and/or other copyright owners and it is a condition of accessing publications that users recognise and abide by the legal requirements associated with these

- Users may download and print one copy of any publication from the public portal for the purpose of private study or research.

- You may not further distribute the material or use it for any profit-making activity or commercial gain

If the publication is distributed under the terms of Article $25 \mathrm{fa}$ of the Dutch Copyright Act, indicated by the "Taverne" license above, 


\title{
Do treatment-induced changes in arterial stiffness affect left ventricular structure? A meta-analysis
}

\author{
Koen M. van der Waaij ${ }^{a, b}, *$ Maarten H.G. Heusinkveld ${ }^{a, *}$, Tammo Delhaas $^{a}$, Abraham A. Kroon $^{b}$, \\ and Koen D. Reesink ${ }^{a}$
}

See editorial comment on page $\mathbf{2 8 0}$

Background: Vascular research demonstrated that pulse wave velocity (PWV), a measure of arterial stiffness, is inherently blood pressure dependent. Considering the hypothesized pathophysiological chain of increased arterial stiffness leading to increased blood pressure load with consequent left ventricular hypertrophy (LVH) development, we conducted a systematic review of antihypertensive and lifestyle intervention studies to determine the association between, on the one hand, changes in arterial stiffness and blood pressure, and, on the other hand, changes in left ventricular mass (LVM).

Methods: Using PubMed, EMBASE, Cochrane and Web of Science, we identified 23 studies, containing 2573 patients. Studies reported changes in arterial stiffness (assessed by means of PWV), SBP, DBP and LVM index (LVMI), respectively.

Results: Statistically significant reductions in SBP, PWV and LVMI were reported in 16, 14 and 20 studies, respectively. Pooled analysis of studies showed that the proportion in SBP reduction did not correlate significantly to the proportion in reductions of the other two variables. On the contrary, we found a significant positive correlation $(r=0.61, P=0.003)$ between arterial stiffness and reduction of $L V M$, expressed as a relevant reduction in LVMI of $6.9 \mathrm{~g} / \mathrm{m}^{2}$ per $1.0 \mathrm{~m} / \mathrm{s}$ reduction in PWV.

Conclusion: Our findings provide evidence that a decrease in arterial stiffness is associated with reduction of LVM. To investigate whether there exists a causal relation between LVH due to arterial stiffness increases and in turn blood pressure load increases, future studies should strive for a multiple follow-up design and use of blood pressure independent or corrected stiffness indices.

Keywords: aging, diastolic dysfunction, hypertensive heart disease, left ventricular hypertrophy, ventricular-vascular coupling

Abbreviations: $A_{0}$, diastolic cross-sectional lumen area; CC, compliance; $\mathrm{Cl}$, confidence interval; LVM, left ventricular mass; LVMI, left ventricular mass index; PWV, pulse wave velocity; $\rho$, blood density

\section{INTRODUCTION}

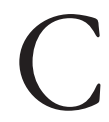

urrently, cardiovascular disease (CVD) is the number one killer of humans worldwide, responsible for 17.7 million deaths (approximately 30\% of all deaths) each year [1]. In the elderly, CVD accounts for even more than $80 \%$ of all deaths [2]. High arterial blood pressure is a key determinant of CVD [3] and is the leading attributable factor for developing heart failure [4]. Elevated isolated SBP is becoming increasingly relevant in the ageing population, as $60 \%$ of people aged 60 years or older have elevated SBP (>140 $\mathrm{mmHg}$ ) [5].

The (age-related) stiffening of arteries has been identified as a key determinant and precursor of elevated SBP [68]. The main contributors to elevated SBP are believed to be decreased (central) arterial compliance and increased systolic wave reflection (i.e. earlier arrival of reflected pressure wave) [7]. Increased myocardial afterload due to elevated SBP affects the way the left ventricle (LV) adapts and becomes hypertrophic [9]. Recently, the European Society of Hypertension/European Society of Cardiology (ESH/ ESC) guidelines for the management of hypertension have emphasized the importance of increased arterial stiffness [assessed as pulse wave velocity (PWV)] and left ventricular hypertrophy (LVH) [assessed as left ventricular mass index (LVMI)] in determining the overall cardiovascular risk [10].

A pattern of increased arterial stiffness, high blood pressure and LVH is frequently observed in smaller observational, cross-sectional studies [11-13]. Due to design and study size, such studies are seriously limited in identifying causality. Furthermore, arterial stiffness measurements are inherently blood pressure dependent [14], complicating the causative interpretation of observed changes in both arterial stiffness and left ventricular structure and function.

Considering the current pathophysiological paradigm linking arterial stiffening, elevation of SBP and development of LVH/failure [15], our aim was to review the available randomized control trials (RCTs) and cohort studies, reporting intervention-induced changes in blood pressure,

Journal of Hypertension 2019, 37:253-263

${ }^{a}$ Department of Biomedical Engineering and ${ }^{b}$ Department of Internal Medicine, CARIM School for Cardiovascular Diseases, Maastricht University Medical Centre, Maastricht, the Netherlands

Correspondence to Maarten H.G. Heusinkveld, MSc, Biomedical Engineering, CARIM School for Cardiovascular Diseases, Maastricht University Medical Centre, P.O. Box 616, Maastricht 6200 MD, the Netherlands Tel: +31 43 3881659;

e-mail: m.heusinkveld@maastrichtuniversity.nl

*Koen M. van der Waaij and Maarten H.G. Heusinkveld contributed equally to this work

Received 17 May 2018 Accepted 30 July 2018

J Hypertens 37:253-263 Copyright (C) 2018 Wolters Kluwer Health, Inc. All rights reserved.

DOI:10.1097/HJH.0000000000001918 
arterial stiffness and left ventricular structure/function as primary outcomes. We evaluated whether interventioninduced changes in arterial stiffness correlated with improvement in left ventricular structure and function. In our meta-analysis, we included the orders of magnitude of changes in PWV and of changes in LVM, in relation to changes in SBP and DBP.

\section{MATERIALS AND METHODS}

\section{Protocol and registration}

In this study, we applied the Preferred Reporting Items for Systematic reviews and Meta-Analyses (PRISMA) statement for studies evaluating medical interventions [16].

\section{Search strategy and study selection}

We extensively searched the PubMed, EMBASE, Cochrane and Web of Science databases using the following search strategy: $(((()((()(($ Heart Failure, Diastolic[MeSH Terms]) OR Heart Failure, Diastolic) OR diastolic dysfunction) OR isolated systolic hypertension) OR pulse pressure) OR Blood pressure[MeSH Terms] )) AND ((((((((Hypertrophy, Left Ventricular[MeSH Terms]) OR Hypertrophy, Left Ventricular) OR left ventricle hypertrophy) OR cardiac hypertrophy) OR cardiomegaly[MeSH Terms]) OR cardiomegaly $))$ AND ((( (((blood pressure) OR blood pressure[MeSH Terms]) OR hypertension[MeSH Terms]) OR high blood pressure) OR hypertension $))$ AND ( ((( ((arterial stiffness) OR vascular stiffness[MeSH Terms]) OR vascular stiffness) OR pulse wave velocity) OR pulse wave analysis[MeSH Terms]) OR pulse wave analysis) OR distensibility $))))$ AND ((((physical activity*) OR motor activity) OR Motor activity[MeSH Terms]) OR ((( ((()((revalidation) OR Exercise[MeSH Terms]) OR Exercise) OR Life Style[MeSH Terms]) OR Life Style) OR Therapeutics[MeSH Terms]) OR Therapeutics) OR medical treatment) OR medication)))). The starting date was determined as 1 January 1990 and the search was updated till 20 April 2017. The reference lists and citations of the obtained articles were hand-searched for additional searches.

Articles were included in this review if they fulfilled the criteria described as follows (Fig. 1):

1. English-written RCTs, prospective observational studies or case-control studies, investigating both an intervention and control group, examining the relationship between arterial stiffness and (diastolic) heart failure in isolated SBP, or the effects of medication, several compounds and lifestyle (diet/exercise) on blood pressure, arterial stiffness and cardiac structure/function, in human follow-up studies (individuals acting as their own controls).

2. Individuals with isolated systolic hypertension and/ or heart failure. No restrictions on age were enforced. Both sexes were included.

3. Studies investigating (primary) outcome measures (see summary measures).

Studies were excluded if populations with kidney hemodialysis/peritoneal dialysis were examined (possible hemodynamic interference), if the estimated glomerular filtration rate (eGFR) was lower than $30 \mathrm{ml} / \mathrm{min}$ per $1.73 \mathrm{~m}^{2}$, if there were no ventricular or vascular changes reported or if the studies were classified as retrospective cohort and/or crosssectional studies. In addition, review articles and case reports were not eligible for inclusion.

\section{Study selection and data extraction}

When eligibility criteria and the search strategy were realized by three investigators (K.M.W, A.A.K. and K.D.R.), selection screening, based on title and abstract according to the a priori retrieved inclusion and exclusion criteria, was conducted. In case of mismatch between the investigators, inclusion of an article was based on an agreement by consensus during the selection screening. Full-text publications were reviewed by two investigators (K.M.W. and M.H.G.H.) if eligibility criteria were satisfied. Study characteristics, risk of bias within studies and results/conclusions of individual studies were reviewed independently of each other. From the selected studies, when available, the following data were extracted: study methods (design, data collection, follow-up time), participant characteristics (inclusion/exclusion, size, origin, setting), intervention/ placebo treatment (type, dose, duration) and outcome measures. In case of a mismatch between first and second reviewer, agreement was achieved by consensus.

\section{Risk of bias}

Two reviewers (K.M.W. and M.H.G.H.) independently assessed the risk of bias to ascertain the validity of the included studies. If present, discrepancies were resolved by an agreement based on consensus. Using the online Cochrane handbook for writing systematic reviews [17], sequence generation, allocation concealment, randomization, blinding of participants and personnel, proportion of drop-outs, similarity between therapies, selective outcome reporting and sponsors influence were assessed for RCTs. Prospective observational studies were assessed by the Newcastle-Ottawa Scale [18], in which selection, comparability and exposure parameters were rated.

\section{Summary measures}

Primary outcome measures were changes in arterial stiffness, for example quantified by PWV, blood pressure, LVH, LVM and LVMI, and diastolic heart failure indices, and particularly relations between those variables. The studies included reported, on the one hand, regional pulse wave velocities (i.e. cfPWV and baPWV, based on transit time) and, on the other hand, single-point aortic stiffness (i.e. compliance and distensibility). The included studies did not utilize carotid measurements. Subsequently, from aortic stiffness estimates, we obtained estimates of aoPWV using the Bramwell-Hill equation [19]. In case compliance (CC) was reported, we used the equation PWV $=\left[A_{0} /(\rho \mathrm{CC})\right]^{1 / 2}$, whereas for distensibility (DC), we used the equation PWV $=[1 /(\rho \mathrm{DC})]^{1 / 2}$ (see ${ }^{*}$ in Table S3, http://links.lww.com/ $\mathrm{HJH} / \mathrm{B} 3)$. Here, $A_{0}$ is the diastolic cross-sectional area, defined $A_{0}=0.25 \pi$ diameter $^{2}$ and $\rho$ blood density, assumed $1050 \mathrm{~kg} / \mathrm{m}^{3}$. In total, six studies reported cfPWV, four studies reported baPWV and five studies reported aortic distensibility or compliance as arterial stiffness 


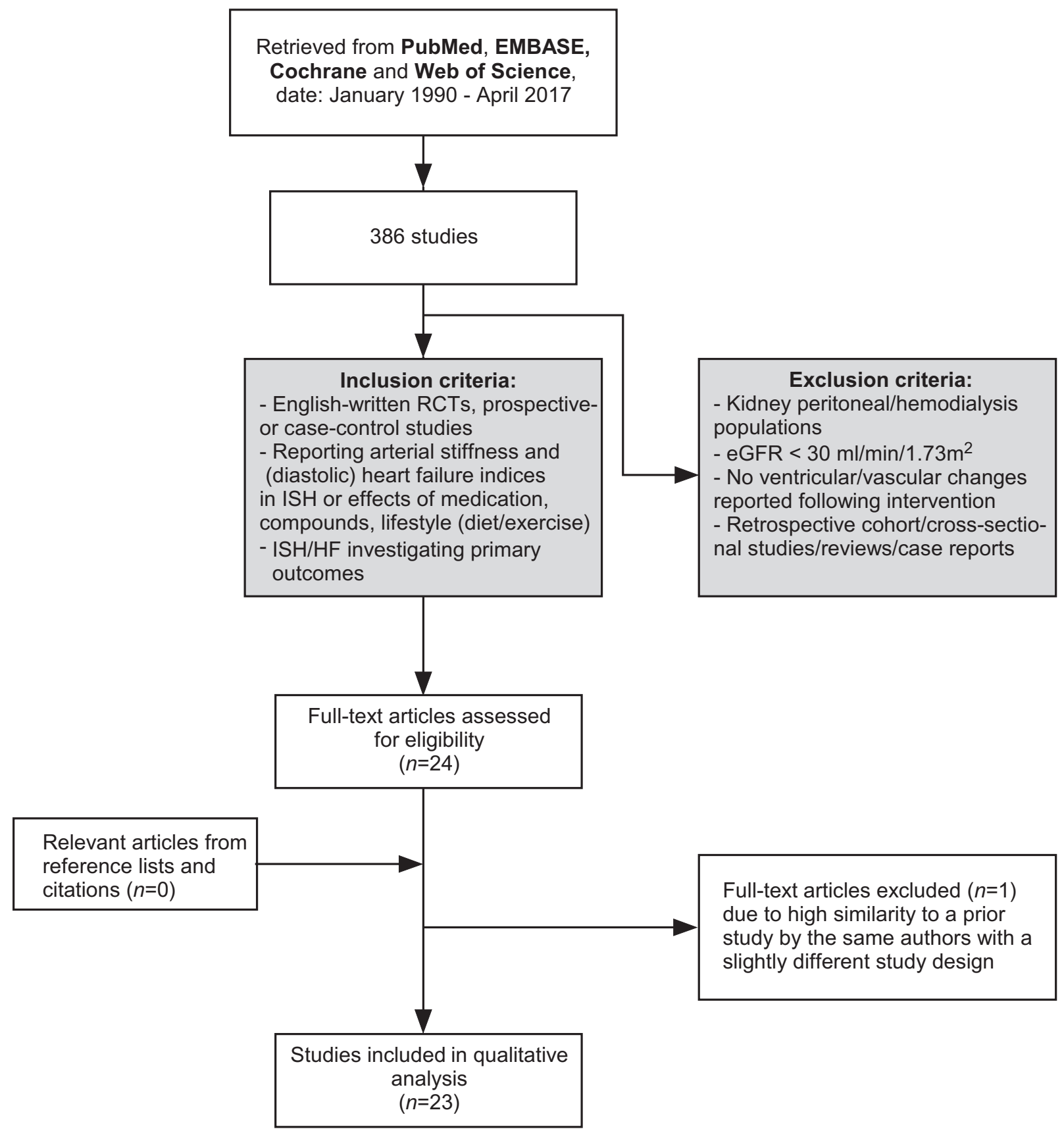

FIGURE 1 Search and selection of studies.

outcome, respectively (Table 1). Although pulse pressure was included in our search strategy, we did not include these results in our analysis to avoid interpreting them as arterial stiffness measures. For studies reporting LVMI using LVM indexed by height ${ }^{2.7}$, we recalculated LVMI using LVM/height ${ }^{2}$ (see * in Table S3, http://links.lww.com/ $\mathrm{HJH} / \mathrm{B} 3)$.

\section{Outcome of interest and statistical analyses}

For each study, we extracted average primary outcomes measures per treatment arm. The outcomes were analyzed for normality using visual inspection of histograms and quantile-quantile plots. Data were visualized using scatter plots, whereas Pearson's correlation coefficients and linear regression coefficients were calculated to explore betweenstudy associations between changes in PWV and SBP, LVMI and SBP, and LVMI and PWV, respectively. To internally validate our findings, we performed a sensitivity analysis of the correlation and regression parameters by repeating the statistical analyses after omission of studies not specifically reporting the effect of antihypertensive medication. In addition, we repeated the statistical analyses using only the data from RCTs. A $P$ value of less than 0.05 was considered statistically significant. All statistical analyses were performed using SPSS version 24 (IBM Corp, Armonk, New York, USA). 
TABLE 1. Overview of arterial stiffness measured

baPWV, brachial pulse wave velocity; cfPWV, carotid-femoral pulse wave velocity; aoPWV, aortic pulse wave velocity.

\section{RESULTS}

\section{Study selection}

Using our search strategy, we identified 386 potentially relevant articles from PubMed $(n=221)$, EMBASE $(n=1)$, Cochrane $(n=50)$ and Web of Science $(n=114)$. A flow diagram of the study selection process is shown in Fig. 1. Eventually, 23 articles with a total of 2573 individuals met the inclusion and eligibility criteria and were included in this review [20-42].

\section{Risk of bias}

The quality of the different included studies varied. For RCT-studies (Table S1, http://links.lww.com/HJH/B3), the domains 'allocation concealment', 'blinding of participants and personnel' and 'blinding of outcome assessment' constituted a plausible risk of bias for most studies. Thereby, the outcome for these individual studies is negatively influenced, which could lead to high risks of performance bias. To the contrary, most studies demonstrated adequate 'sequence generation', 'follow-up of patients' and 'similarity of therapies'. In addition, low chance of publication bias was indicated, via adequate exclusion of 'undesirable influences of sponsors' and 'selective-free outcome reporting'. For cohort studies (Table S2, http://links.lww.com/HJH/ B3), the domains 'selection', 'comparability' and 'exposure' were adequate, indicating a low risk of bias. Two studies [38,42], however, constituted overall a significantly higher risk of bias, and therefore, extra attention is needed when interpreting their results.

\section{Study characteristics}

The characteristics of included studies are summarized in Tables 2 and 3. Fourteen studies were qualified as RCTs, while the other nine were prospective observational cohort studies. The follow-up period ranged from 3 months to 4.8 years for all English-written studies. The number of participants ranged from $n=20$ to $n=873$. Mainly, essential hypertensive patients with or without cardiac and/or vascular alterations were included in studies in single-centre tertiary care centres in European and East Asian countries. The main exclusion criteria were cerebrovascular and/or renal disorders. The majority of the trials used antihypertensive drugs, such as angiotensin II receptor blockers (ARBs), angiotensin-converting enzyme inhibitors (ACEIs), calcium channel blockers (CCBs), diuretics and beta-blockers, while other trials examined the effects of either weight loss, physical training, surgery, treatment with agalsidase beta or high doses of allopurinol. Outcome measures included changes in vascular stiffness, LVM and left ventricular diastolic function parameters, and correlations between those variables.

\section{Studies with vascular and ventricular outcome variables}

A total of 13 studies reported values on changes in SBP, PWV and LVMI after intervention (Fig. 2). The remaining 10 studies, reporting only one or two of the outcome variables, are not displayed in Fig. 2 (data given in Table S3, http:// links.lww.com/HJH/B3). At study level, changes in SBP seemingly correlated with reductions in both PWV and LVMI. Ripley et al. [24] reported no substantial differences between the change in SBP, PWV and LVMI among treatment arms (Fig. 2). Conversely, three studies [26,28,31] reported considerably different PWV reductions within treatment arms, despite a similar reduction in SBP. Takami and Saito [26] consisted of two treatment arms comparing two types of ARB/CCB treatment, whereas Anan et al. [31] consisted of three treatment arms (Fig. 2). Tomiyama et al. [28] consisted of an ARB treatment arm and a CCB treatment arm, respectively. Furthermore, in studies consisting of two or more treatment arms, it appeared that the study arm with the highest reduction in PWV and SBP, consistently corresponded to the treatment arm with the highest reduction in LVMI.

\section{Blood pressure in relation to vascular and ventricular changes}

Table 4 summarizes changes in PWV and LVMI stratified by mean changes $(\Delta)$ in SBP and DBP, defined by pressure ranges $\Delta \mathrm{DBP}$ at least $-7 \mathrm{mmHg}$ versus $\Delta \mathrm{DBP}$ less than $-7 \mathrm{mmHg}$, and $\Delta \mathrm{SBP}$ at least $-13 \mathrm{mmHg}$ versus $\Delta \mathrm{SBP}$ less than $-13 \mathrm{mmHg}$, respectively. The choice of the pressure ranges was based on twice the intrasession standard deviation for DBP and SBP, as reported earlier [14]. We found that greater reductions in blood pressure (both SBP as DBP) were indicative for greater PWV reductions, whereas for LVMI reductions, this pattern only appears to hold for greater DBP-changes (Table 4).

\section{Pooling of data and correlations between SBP, PWV and LVMI within studies reporting all three variables}

We pooled and plotted $\Delta \mathrm{SBP}, \Delta \mathrm{PWV}$ and $\Delta \mathrm{LVMI}$ data to explore potential associations among these outcome measures (Fig. 3). Regarding SBP, the proportion in reduction did not correlate significantly to the proportion in reductions of the other two outcome measures (i.e. $\Delta \mathrm{PWV}$ versus $\Delta$ SBP: $r=0.23, P=0.29 ; \Delta$ LVMI versus $\Delta$ SBP: $r=-0.05$, $P=0.81)$. However, we found a significant positive correlation between changes in $\triangle \mathrm{PWV}$ and $\triangle \mathrm{LVMI}$ (Fig. 3, 


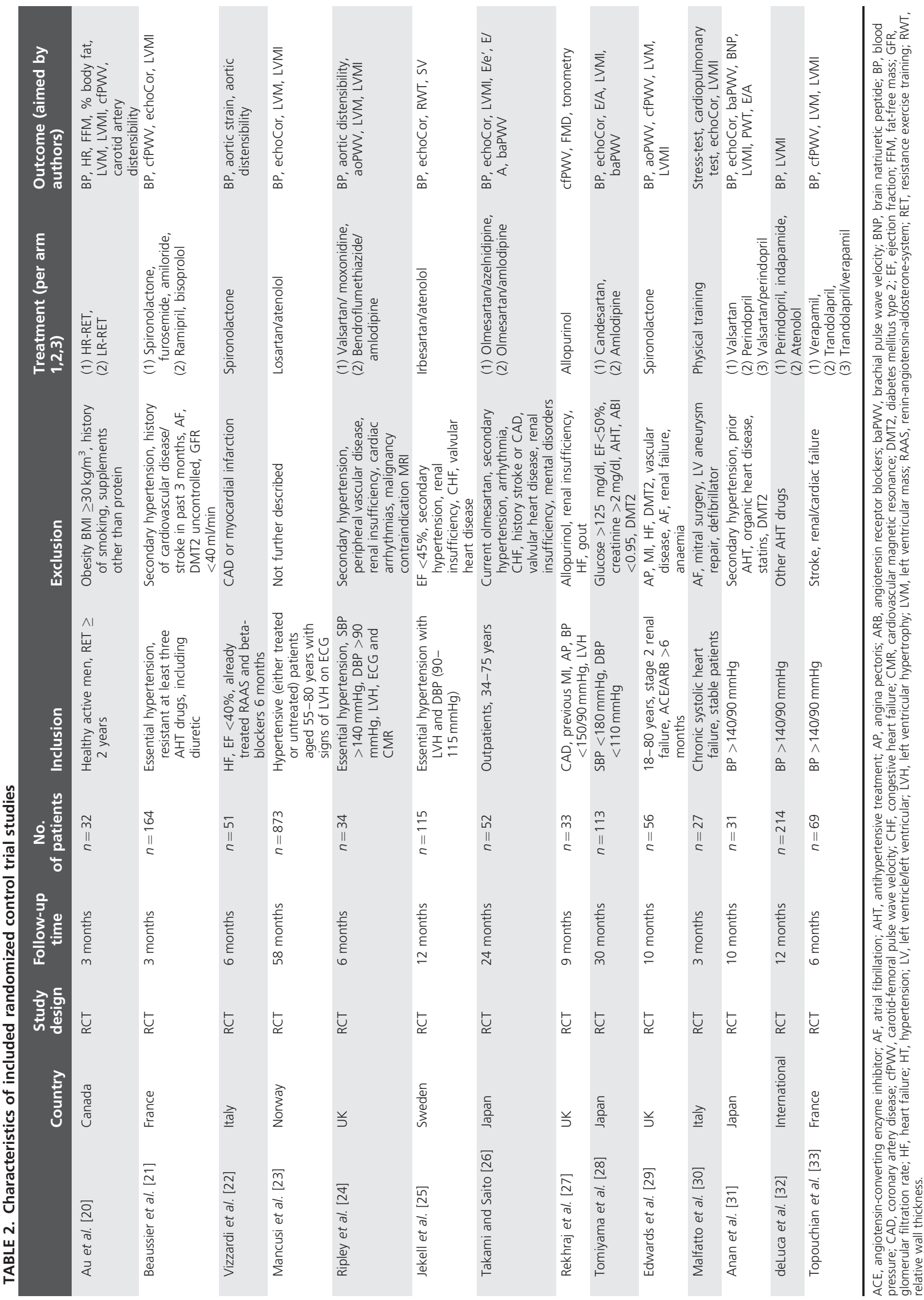



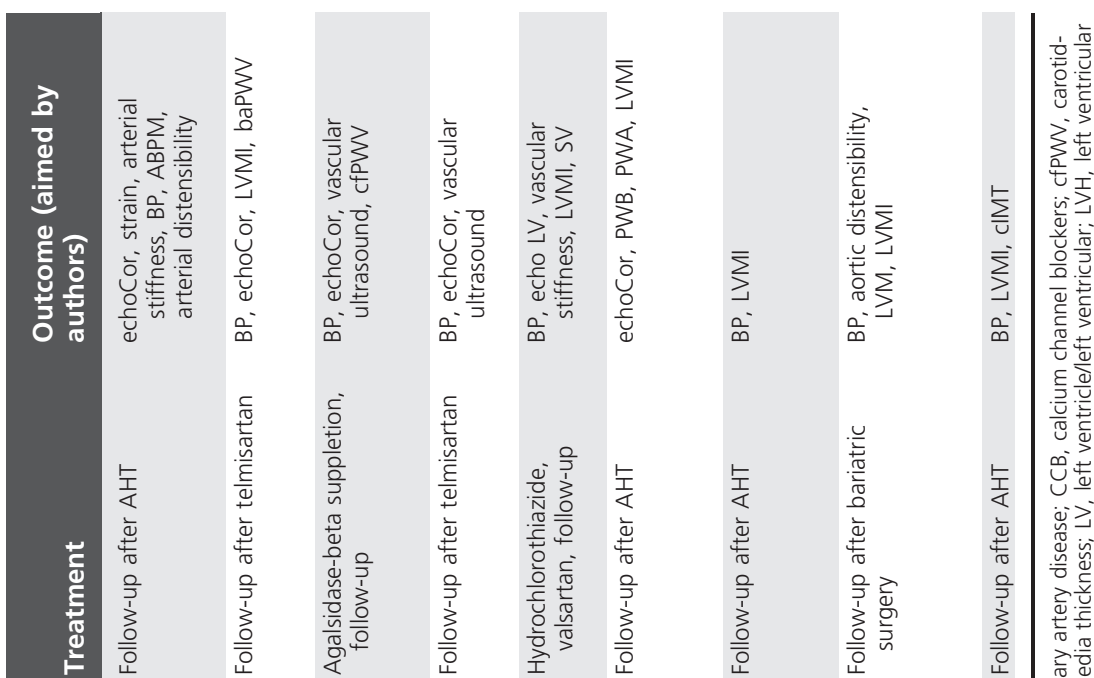

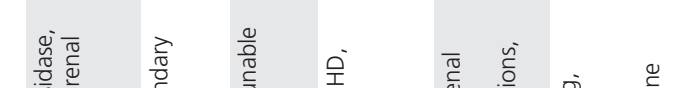

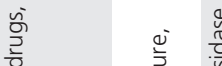

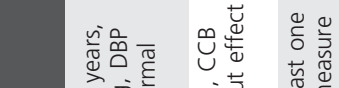

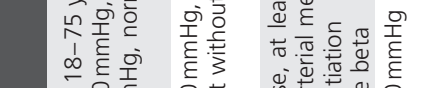
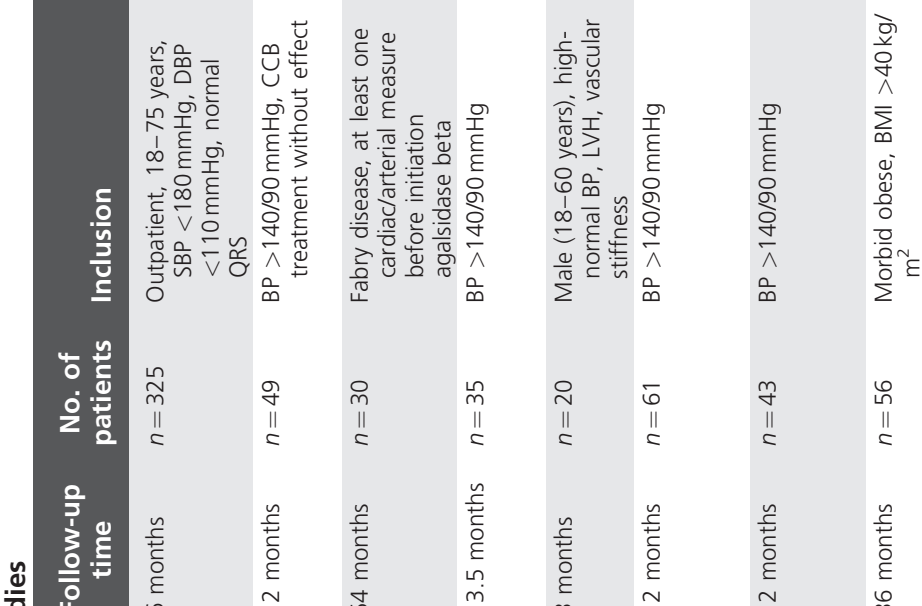

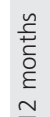
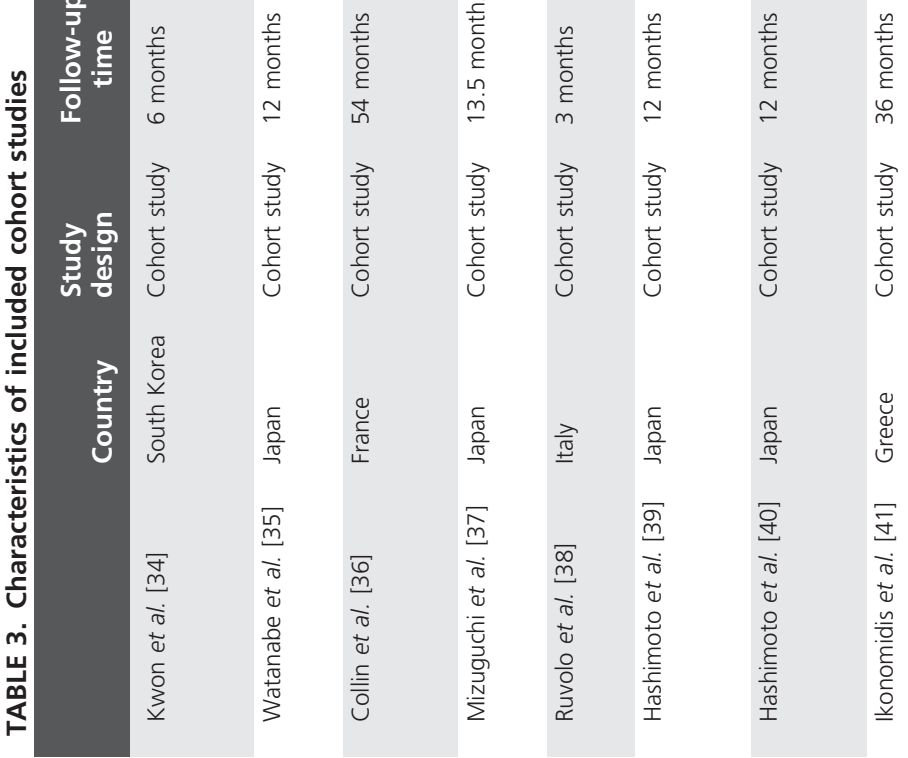

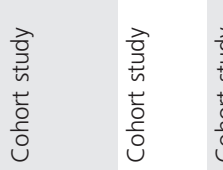

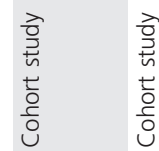

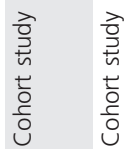

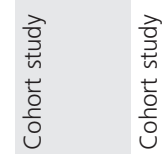
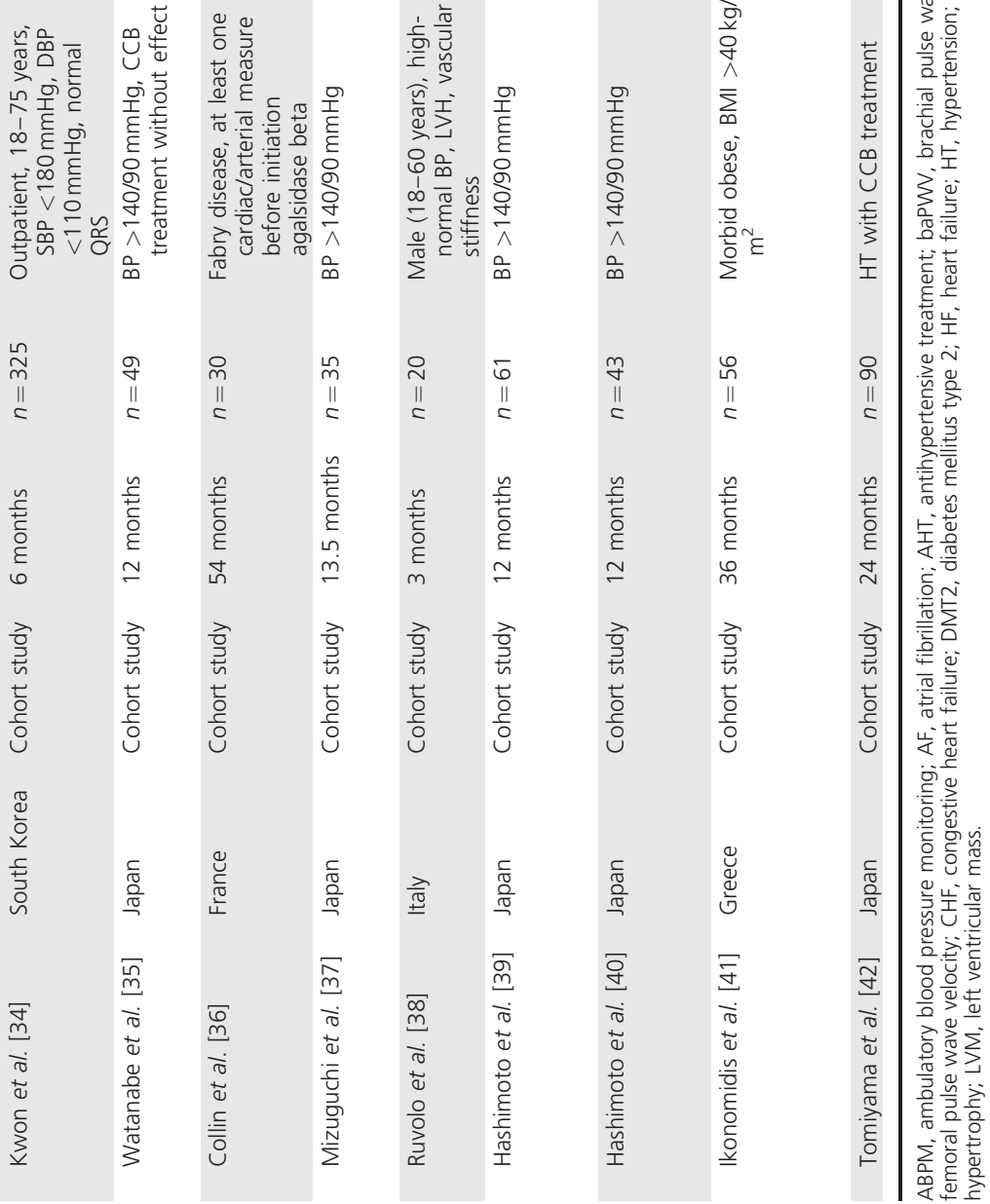


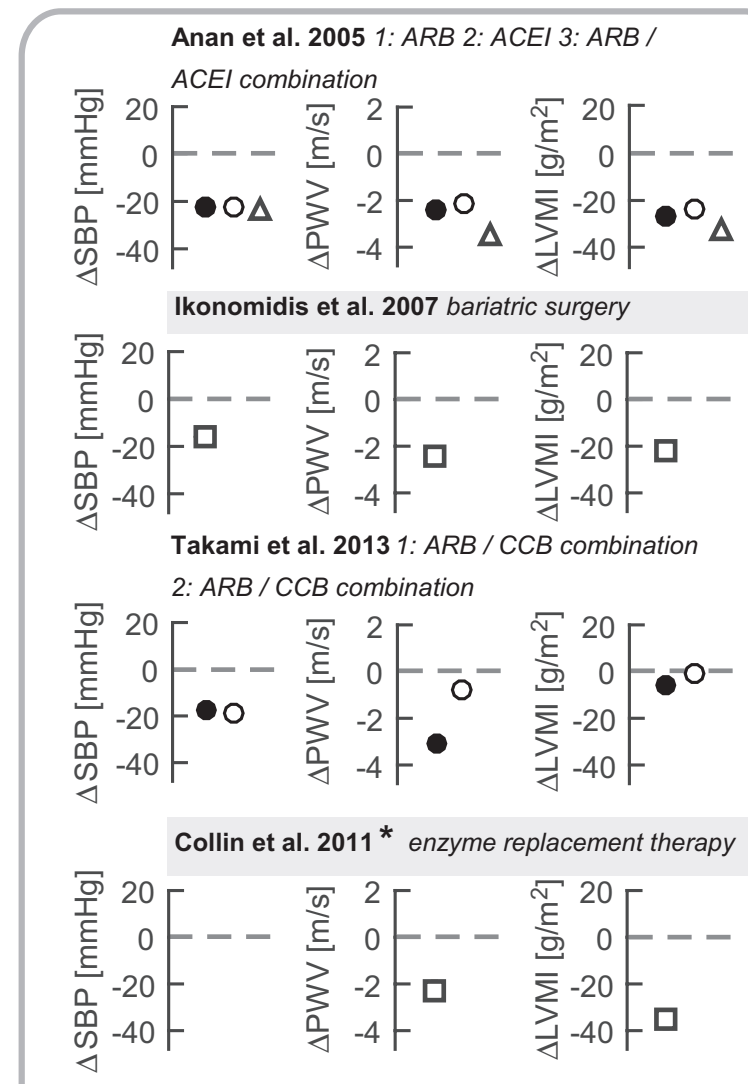

Topouchian et al. 1999 1: $A R B$ 2: ACEI 3: ARB / ACEI combination

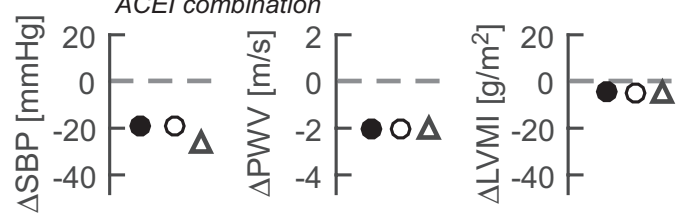

Ruvolo et al. 2010 ARB / Diuretic combination

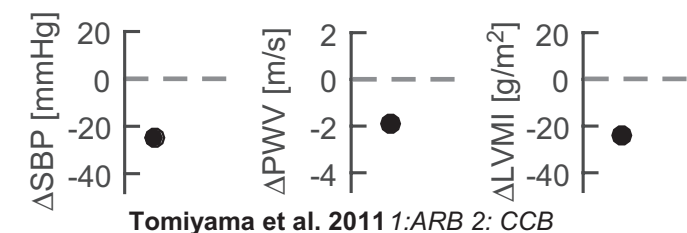

Tomiyama et al. 20111:ARB 2: $C C B$

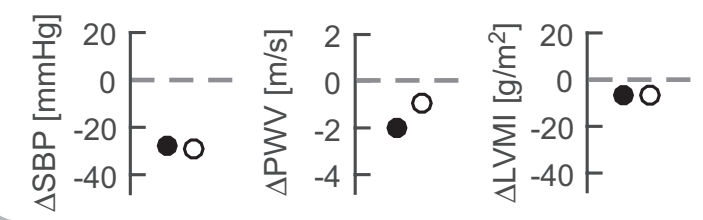

Watanabe et al. $2013 A R B$

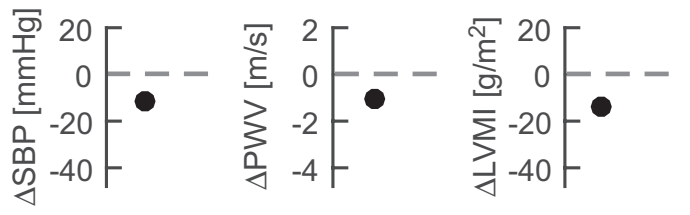

Ripley et al. 2014 1: $A R B$ 2: $C C B$

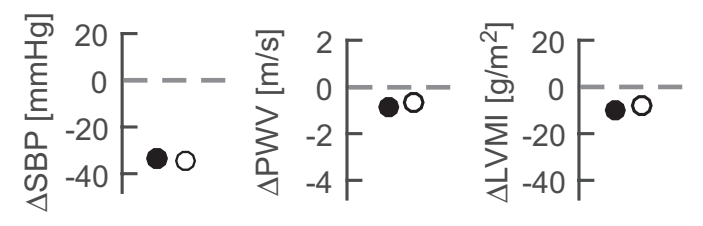

Edwards et al. 2009 Diuretic

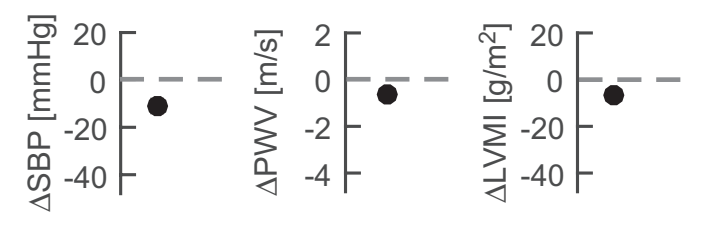

Beaussier et al. 2015 1: $A R B$ / CCB / Diuretic

combination 2: ACEI / BB / Diuretic combination

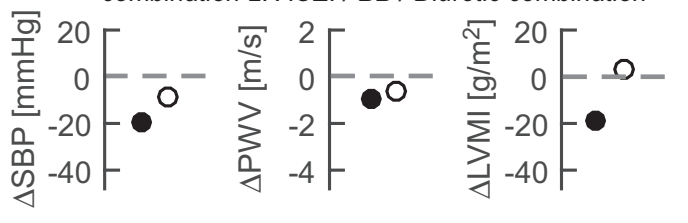

Hashimoto et al. 2008 one of the five classes of antihypertensive agents (ESH / ESC guidelines)

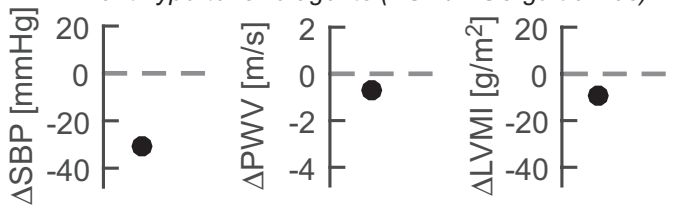

Rekhraj et al. 2012 Allopurinol

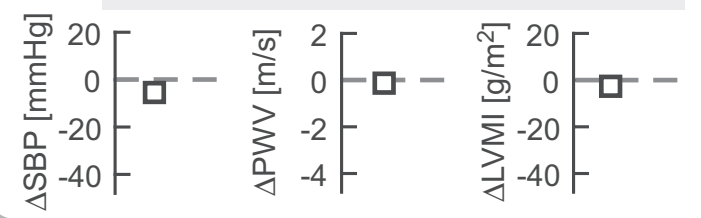

FIGURE 2 Effect of intervention on mean changes in SBP $(\triangle \mathrm{SBP})$, pulse wave velocity $(\Delta \mathrm{PWV}$ ) and left ventricular mass index ( $\Delta$ LVMI). Studies are listed according to magnitude of $\triangle \mathrm{PWV}$, from largest (top-left) to smallest (bottom-right). Ten of the 12 studies had antihypertensive medication as intervention (circles, triangles), while two (squares) had other interventions, as indicated. Symbols indicate treatment arms (i.e. closed circle $=$ arm 1, open circle $=$ arm 2, triangle $=$ arm 3). ACEl, angiotensin-

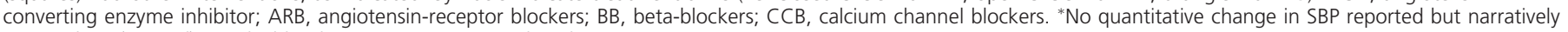
reported as '(Central) systolic blood pressure were not reduced'.

$r=0.61, P=0.003)$. Furthermore, linear regression of $\triangle$ PWV on $\Delta$ LVMI suggested a $6.9 \mathrm{~g} / \mathrm{m}^{2}$ decrease in LVMI per $1 \mathrm{~m} / \mathrm{s}$ decrease in PWV $\left[95 \% \mathrm{CI}=(1.9-11.8) \mathrm{g} / \mathrm{m}^{2} / \mathrm{m} / \mathrm{s}\right]$. The analyses were repeated following omission of the nonantihypertensive treatment studies [20,27,30,36,41]. Briefly, this caused only minor changes in the correlation and regression parameters $[r=0.57, P=0.013$, and $\beta=$ $6.5 \mathrm{~g} / \mathrm{m}^{2} / \mathrm{m} / \mathrm{s}, 95 \% \mathrm{CI}=(1.6-11.4) \mathrm{g} / \mathrm{m}^{2} / \mathrm{m} / \mathrm{s}$, respectively]. Similarly, we found minor changes in the correlation and regression parameters when using only data from RCTs $\left[r=0.62, P=0.010\right.$, and $\beta=6.6 \mathrm{~g} / \mathrm{m}^{2} / \mathrm{m} / \mathrm{s}, 95 \% \mathrm{CI}=(1.9-$ 11.4) $\mathrm{g} / \mathrm{m}^{2} / \mathrm{m} / \mathrm{s}$. Given the limited amount of data points 
van der Waaij et al.

TABLE 4. Blood pressure changes and associated changes in pulse wave velocity and/or left ventricular mass index

\begin{tabular}{lcc} 
& Changes in PWV & Changes in LVMI \\
\hline BP change $(\mathbf{m m H g})$ & $\Delta \mathbf{P W V}(\mathbf{m} / \mathbf{s})$ & $\Delta \mathbf{L V M I}\left(\mathbf{g} / \mathbf{m}^{\mathbf{2}}\right)$ \\
\hline $\mathrm{DBP} \geq-7$ & $-0.9(-3.2,-0.14)[20,26,27,41]$ & $-7.3(-22,-2.8)[26,27,29,41,42]$ \\
$\Delta \mathrm{DBP}<-7$ & $-2.0(-3.7,-0.6)[24,28,31,33,35,38,39]$ & $-11(-35,-3.9)[23,24,31,33-35,38-40]$ \\
$\Delta \mathrm{SBP} \geq-13$ & $-0.8(-2.4,-0.14)[20,21,27,29,35,41]$ & $-13(-24,+4.5)[21,35,41,42]$ \\
$\Delta \mathrm{SBP}<-13$ & $-2.0(-3.7,-0.7)[24,26,28,31,33,38,39]$ & $-8.0(-35,-2.8)[23,24,26,31,33,34,38-40]$ \\
\hline
\end{tabular}

Values are presented as median (minimum, maximum).

$\triangle \mathrm{DBP}$ and $\triangle \mathrm{SBP}$, change in DBP and SBP; BP, blood pressure; LVMI, left ventricular mass index; PWV, pulse wave velocity

available for regression analysis (Fig. 3), we chose not to evaluate quadratic instead of linear associations, as this would result in overfitting. We explored possible mutual relationships between types of $\Delta \mathrm{PWV}$ (i.e. as assessed by
cfPWV, baPWV and aoPWV) with both $\triangle \mathrm{SBP}$ and $\triangle \mathrm{LVMI}$ (Figure S1, http://links.lww.com/HJH/B3). Our analysis did not demonstrate statistically significant associations. Nevertheless, in particular, $\Delta$ baPWV and $\Delta$ aoPWv, but not
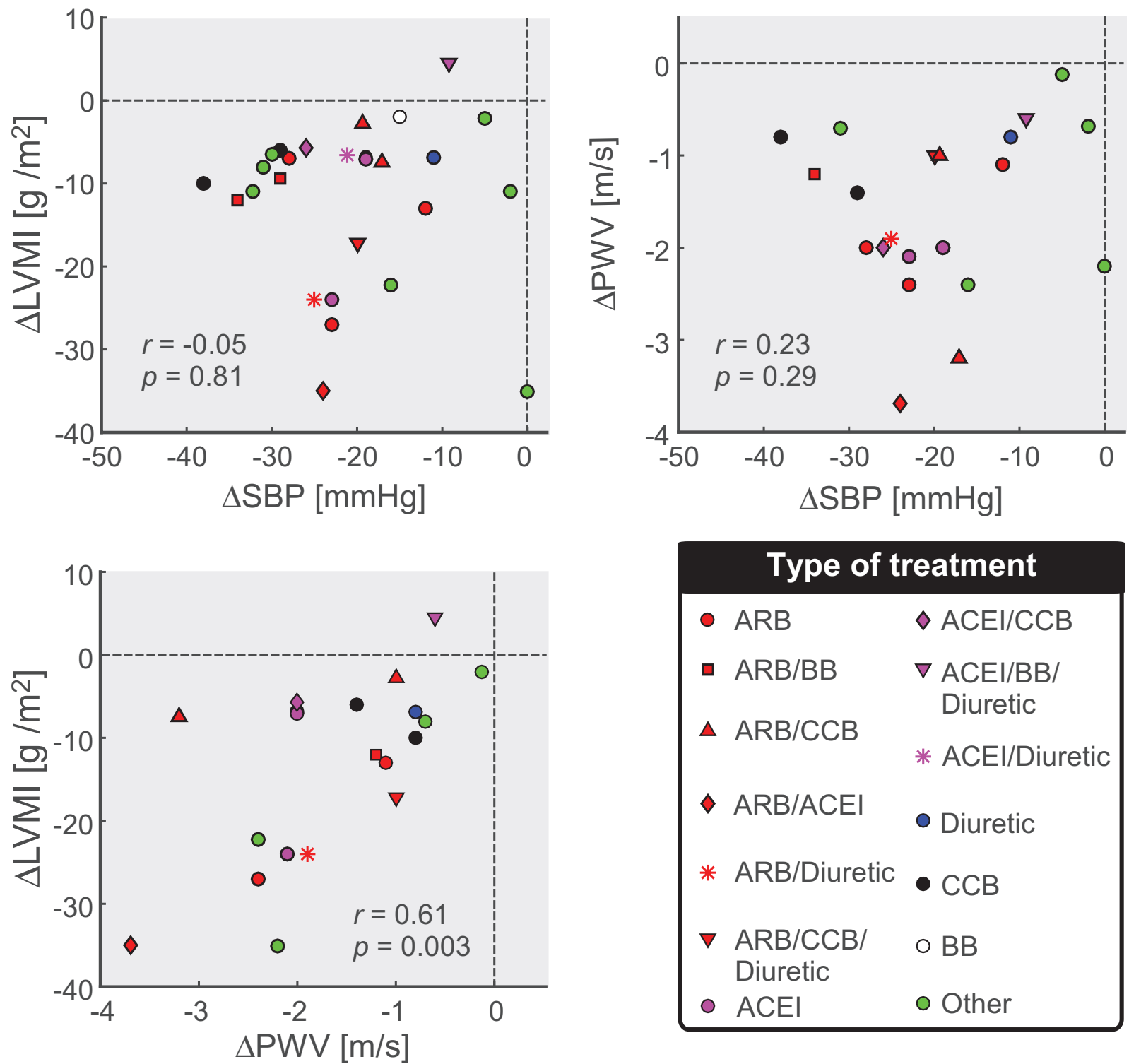

\begin{tabular}{|ll|}
\hline \multicolumn{2}{|c|}{ Type of treatment } \\
$\bullet$ ARB & $\diamond$ ACEI/CCB \\
$\nabla$ ARB/BB & $\nabla$ ACEI/BB/ \\
$\Delta$ ARB/CCB & Diuretic \\
$\diamond$ ARB/ACEI & $*$ ACEl/Diuretic \\
$*$ ARB/Diuretic & $\bullet$ CCB \\
$\nabla$ ARB/CCB/ & $\circ \mathrm{BB}$ \\
Diuretic & A Other \\
\hline ACEI &
\end{tabular}

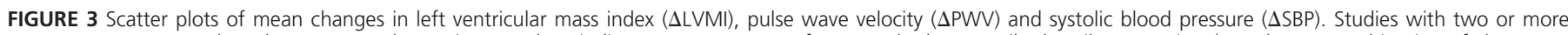

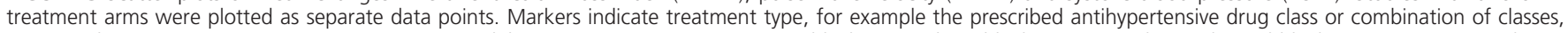

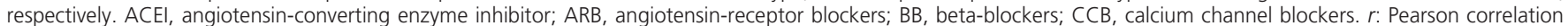
coefficient. $P$ : statistical significance level. 
$\Delta$ cfPWV, showed trends with $\Delta$ LVMI $(r=0.62, P=0.10$; $r=0.83, P=0.08 ; r=0.26, P=0.54$, respectively). Furthermore, $\Delta$ cfPWV and $\triangle$ aoPWV, but not $\Delta$ baPWV, showed trends with $\Delta$ SBP $(r=0.59, P=0.07 ; r=-0.85, P=0.07$; $r=0.14, P=0.74$, respectively), indicating that a larger power (in future studies) might possibly lead to significant correlations. In the above analyses, a limited amount of data points was available (Figure S1, http://links.lww.com/HJH/ B3).

\section{DISGUSSION}

\section{Key findings}

Our review of well controlled clinical intervention studies provides evidence that a decrease in arterial stiffness could contribute to the reduction of LVM in (hypertensive) patients. However, we could not obtain convincing evidence supporting the causative pathophysiological (arterial stiffening - elevated SBP - LV hypertrophy/failure)-chain. A major complication is that arterial stiffness measurements such as PWV are inherently blood pressure dependent $[14,43]$. In the present review, we found studies showing a significant decrease in PWV in excess of nearly $0.5 \mathrm{~m} / \mathrm{s}$, which is typically the measurement variability order of magnitude, and in excess of $1 \mathrm{~m} / \mathrm{s}$, which our group identified as the change in PWV expected for a change in DBP of $10 \mathrm{mmHg}$ [14]. As such, some of the observed significant changes in PWV may partially or fully be attributable to a change in blood pressure, without a change in intrinsic arterial stiffness. We did not find a study that was appropriately designed to disentangle pressure-independent arterial stiffness effects from plain blood pressure lowering, nor are we aware of a study that extensively described SBP, PWV and LVMI changes over many time-points. We expect that changes in PWV come before changes in left ventricular mass. There were several studies included reporting arterial stiffness and ventricular structure at multiple time-points [26,28,36,41]. However, only data from Collin et al. [36] suggested that a change in PWV could precede a change in left ventricular mass. Despite the present analysis, therefore, it remains cumbersome to assess the direct effect of antihypertensive treatment on left ventricular structure and function as well as test the hypothesized causal relation between increased arterial stiffness and LVH.

\section{Clinical implications and future work}

Our results indicate a significant positive correlation between changes in arterial stiffness and LVM. Only two of the 23 included studies [26,34] reported changes in left ventricular diastolic function indices (i.e. the outcome variables E/A and E/e', respectively). Those studies found independent statistical associations between, on the one hand, reductions in PWV and pulse wave reflection magnitude (assessed by means of augmentation index), and, on the other hand, improvements in left ventricular diastolic function (via LVMI reduction and improvements in $\mathrm{E} / \mathrm{A}$ and E/e', Table S3, http://links.lww.com/HJH/B3). Takami and Saito [26] hypothesized that the mechanism involved could be a delay in arrival of the reflected pulse wave due to decreased PWV, which in turn reduces left ventricular afterload [26]. However, it should be noted that using augmentation index as a proxy for wave reflection magnitude is deemed contentious by some researchers in the field [44]. Hashimoto et al. [39] reported a positive correlation between changes in LVM and reflection magnitude, calculated using a 'gold standard' method of assessing pulse wave reflections (i.e. based on solving the physical laws of mass conservation and momentum balance [15]). The authors reported that reducing stiffness of peripheral muscular arteries, which they considered to be the root cause of increased pulse wave reflection, could be more important than reducing central arterial stiffness, in the reduction of LVM [39]. Tomiyama et al. [28] reported that candesartan leads to significantly greater reductions in stiffness of muscular arteries (i.e. assessed by brachial-ankle PWV), as compared to amlodipine [28], with similar decreases in LVMI of 7 and $6 \mathrm{~g} / \mathrm{m}^{2}$, respectively.

In summary, our results suggest that therapeutic agents that aim to lower arterial stiffness may lead to greater reductions in LVM. However, further clinical trials with multiple follow-up measurements, using pressure-independent arterial stiffness indices, are required to establish the causative role of arterial stiffness-lowering in reduction of LVM. To achieve the latter, a stiffness index such as $\mathrm{CAVI}_{0}$ could be a promising candidate [43]. In addition, directing more attention to pulse wave reflection indices may further advance insight into LVM reduction [26,39]. Of particular interest are (lifestyle or surgical) interventions improving physical activity and diet, as these kinds of trials provided promising results in terms of arterial stiffness and left ventricular diastolic function improvements [20,27,30,36,41], without invoking per se the effects of direct actions of antihypertensive drugs on the cardiovascular system.

\section{Limitations}

Our review is limited by its reliance on published data causing an inherent risk of publication bias, as neutral studies (without changes in LVMI or PWV) are less likely to be accepted by publishers. A general conclusion about the effect size of lowering blood pressure and arterial stiffness on LVH is difficult, as the quality of the studies was variable (i.e. quality rating ranging between 2 and 8 points out of 10 for RCTs, and between 5 and 9 points for cohort studies, Table S1 and S2, http://links.lww.com/HJH/ B3). Most studies quantified arterial stiffness using carotidfemoral PWV or brachial-ankle PWV, calculated using pulse transit time and path length. For studies reporting either a change in compliance or distensibility, we were limited to calculating an estimate of PWV using the Bramwell-Hill equation. Regional (i.e. carotid-femoral and brachial-ankle) PWV values are physically different compared with singlepoint (i.e. aortic) PWV values, calculated using the Bramwell-Hill equation. However, previous work including patient studies $[45,46]$ and mechanistic computational studies [47] showed reasonable proportionality between regional PWV and single-point PWV. Also, the study of Chow and Rabkin [48] showed appropriate proportionality between baPWV and cfPWV. Therefore, we believe that pooling of changes in cfPWV, baPWV and aoPWV can be justified. We, however, cannot exclude that pooling the various methodologies of PWV assessment influenced the associations we found. Furthermore, considering the 
heterogeneity in antihypertensive treatment and the limited number of studies included, we have not been able to conduct antihypertensive drug class specific analyses. Lack of correlation between changes in SBP and LVMI could be related to the fact that most studies included in this review performed office BP measurements instead of 24-h ambulatory $\mathrm{BP}$ measurements. Office blood pressure measurements contain more variable SBP readings, for example due to interindividual differences in white-coat effect. Previously, it was reported that in hypertensive children, 24-h SBP relates with LVMI, but not with office SBP [49]. Lastly, minor limitations of this review include our language restriction for only English written articles, and our inclusion of non-RCT studies, which in the hierarchy of evidence are inferior to RCT studies.

\section{Conclusion}

This review demonstrates that there is evidence in well controlled clinical intervention studies that a decrease in arterial stiffness is associated with a reduction of left ventricular mass. To eliminate blood pressure dependent effects for the correlation between arterial stiffness and left ventricular structure, blood pressure independent markers should be used in future studies. In that way, better identification of potential targets for antihypertensive drug treatment may be facilitated. In addition, the potential of lifestyle interventions (e.g. physical activity and diet) in the research field remains to be emphasized.

\section{ACKNOWLEDGEMENTS}

\section{Conflicts of interest}

The authors have no conflicts of interest.

\section{REFERENGES}

1. World Health Organization. About cardiovascular diseases. 2018. http:// www.who.int/cardiovascular_diseases/en/. [Accessed 1 March 2018]

2. Yazdanyar A, Newman AB. The burden of cardiovascular disease in the elderly: morbidity, mortality, and costs. Clin Geriatr Med 2009; 25:563-577.

3. Lim SS, Vos T, Flaxman AD, Danaei G, Shibuya K, Adair-Rohani H, et al. A comparative risk assessment of burden of disease and injury attributable to 67 risk factors and risk factor clusters in 21 regions, 19902010: a systematic analysis for the Global Burden of Disease Study 2010. Lancet 2012; 380:2224-2260.

4. Tocci G, Sciarretta S, Volpe M. Development of heart failure in recent hypertension trials. J Hypertens 2008; 26:1477-1486.

5. Smulyan H, Mookherjee S, Safar ME. The two faces of hypertension: role of aortic stiffness. J Am Soc Hypertens 2016; 10:175-183.

6. Kaess BM, Rong J, Larson MG, Hamburg NM, Vita JA, Levy D, et al. Aortic stiffness, blood pressure progression, and incident hypertension. JAMA 2012; 308:875-881.

7. Mitchell GF, Hwang SJ, Vasan RS, Larson MG, Pencina MJ, Hamburg NM, et al. Arterial stiffness and cardiovascular events: the Framingham Heart Study. Circulation 2010; 121:505-511.

8. Humphrey JD, Harrison DG, Figueroa CA, Lacolley P, Laurent S. Central artery stiffness in hypertension and aging: a problem with cause and consequence. Circ Res 2016; 118:379-381.

9. Ganau A, Devereux RB, Roman MJ, de Simone G, Pickering TG, Saba PS, et al. Patterns of left ventricular hypertrophy and geometric remodeling in essential hypertension. J Am Coll Cardiol 1992; 19:1550-1558.

10. Mancia G, Fagard R, Narkiewicz K, Redon J, Zanchetti A, Bohm M, et al. 2013 ESH/ESC Guidelines for the management of arterial hypertension: the Task Force for the management of arterial hypertension of the European Society of Hypertension (ESH) and of the European Society of Cardiology (ESC). J Hypertens 2013; 31:1281-1357.
11. Pandey A, Golwala H, Xu H, DeVore AD, Matsouaka R, Pencina M, et al. Association of 30-day readmission metric for heart failure under the hospital readmissions reduction program with quality of care and outcomes. JACC Heart Fail 2016; 4:935-946.

12. Vriz O, Magne J, Driussi C, Brosolo G, Ferrara F, Palatini P, et al. Comparison of arterial stiffness/compliance in the ascending aorta and common carotid artery in healthy subjects and its impact on left ventricular structure and function. Int J Cardiovasc Imaging 2017; $33: 521-531$

13. Boutouyrie P, Laurent S, Girerd X, Benetos A, Lacolley P, Abergel E, et al. Common carotid artery stiffness and patterns of left ventricular hypertrophy in hypertensive patients. Hypertension 1995; 25:651-659.

14. Spronck B, Heusinkveld MH, Vanmolkot FH, Roodt JO, Hermeling E, Delhaas T, et al. Pressure-dependence of arterial stiffness: potential clinical implications. J Hypertens 2015; 33:330-338.

15. Westerhof N, O'Rourke MF. Haemodynamic basis for the development of left ventricular failure in systolic hypertension and for its logical therapy. J Hypertens 1995; 13:943-952.

16. Liberati A, Altman DG, Tetzlaff J, Mulrow C, Gotzsche PC, Ioannidis JP, et al. The PRISMA statement for reporting systematic reviews and metaanalyses of studies that evaluate healthcare interventions: explanation and elaboration. BMJ 2009; 339:b2700.

17. Higgins JPTGSe. Cochrane handbook for systematic reviews of interventions version 510 [updated March 2011]. London, UK: The Cochrane Collaboration; 2011; www.cochrane-handbook.ORG. [Accessed 10 September 2017].

18. Wells GA, B.S., O'Connell D, Peterson J, Welch V, Losos M, Tugwell P. The Newcastle-Ottawa Scale (NOS) for assessing the quality of nonrandomised studies in meta-analyses. 2014 Available from: http:// www.ohri.ca/programs/clinical_epidemiology/oxford.asp. [Accessed 1 March 2018].

19. Bramwell JC, Hill A. Velocity of transmission of the pulse-wave: and elasticity of 441 arteries. Lancet 1922; 199:891-892.

20. Au JS, Oikawa SY, Morton RW, Macdonald MJ, Phillips SM. Arterial stiffness is reduced regardless of resistance training load in young men. Med Sci Sports Exerc 2017; 49:342-348.

21. Beaussier H, Boutouyrie P, Bobrie G, Frank M, Laurent S, Coudore F, et al. True antihypertensive efficacy of sequential nephron blockade in patients with resistant hypertension and confirmed medication adherence. J Hypertens 2015; 33:2526-2533.

22. Vizzardi E, Pina PD, Caretta G, Bonadei I, Sciatti E, Lombardi C, et al. The effect of aldosterone-antagonist therapy on aortic elastic properties in patients with nonischemic dilated cardiomyopathy. J Cardiovasc Med (Hagerstown) 2015; 16:597-602.

23. Mancusi C, Gerdts E, De Simone G, Abdelhai YM, Lonnebakken MT, Boman K, et al. Impact of isolated systolic hypertension on normalization of left ventricular structure during antihypertensive treatment (the LIFE study). Blood Press 2014; 23:206-212.

24. Ripley DP, Negrou K, Oliver JJ, Worthy G, Struthers AD, Plein S, et al. Aortic remodelling following the treatment and regression of hypertensive left ventricular hypertrophy: a cardiovascular magnetic resonance study. Clin Exp Hypertens 2015; 37:308-316.

25. Jekell A, Malmqvist K, Wallen NH, Mortsell D, Kahan T. Markers of inflammation, endothelial activation, and arterial stiffness in hypertensive heart disease and the effects of treatment: results from the SILVHIA study. J Cardiovasc Pharmacol 2013; 62:559-566.

26. Takami T, Saito Y. Azelnidipine plus olmesartan versus amlodipine plus olmesartan on arterial stiffness and cardiac function in hypertensive patients: a randomized trial. Drug Des Devel Ther 2013; 7:175-183.

27. Rekhraj S, Gandy SJ, Szwejkowski BR, Nadir MA, Noman A, Houston JG, et al. High-dose allopurinol reduces left ventricular mass in patients with ischemic heart disease. J Am Coll Cardiol 2013; 61:926-932.

28. Tomiyama H, Yoshida M, Yamada J, Matsumoto C, Odaira M, Shiina K, et al. Arterial-cardiac destiffening following long-term antihypertensive treatment. Am J Hypertens 2011; 24:1080-1086.

29. Edwards NC, Steeds RP, Stewart PM, Ferro CJ, Townend JN. Effect of spironolactone on left ventricular mass and aortic stiffness in earlystage chronic kidney disease: a randomized controlled trial. J Am Coll Cardiol 2009; 54:505-512.

30. Malfatto G, Branzi G, Osculati G, Valli P, Cuoccio P, Ciambellotti F, et al. Improvement in left ventricular diastolic stiffness induced by physical training in patients with dilated cardiomyopathy. J Card Fail 2009; 15:327-333. 
31. Anan F, Takahashi N, Ooie T, Yufu K, Hara M, Nakagawa M, et al. Effects of valsartan and perindopril combination therapy on left ventricular hypertrophy and aortic arterial stiffness in patients with essential hypertension. Eur J Clin Pharmacol 2005; 61:353-359.

32. de Luca N, Mallion JM, O'Rourke MF, O'Brien E, Rahn KH, Trimarco B, et al. Regression of left ventricular mass in hypertensive patients treated with perindopril/indapamide as a first-line combination: the REASON echocardiography study. Am J Hypertens 2004; 17: 660-667.

33. Topouchian J, Asmar R, Sayegh F, Rudnicki A, Benetos A, Bacri AM, et al. Changes in arterial structure and function under trandolaprilverapamil combination in hypertension. Stroke 1999; 30:1056-1064.

34. Kwon BJ, Lee SH, Park CS, Kim DB, Park HJ, Jang SW, et al. Left ventricular diastolic dyssynchrony in patients with treatment-naive hypertension and the effects of antihypertensive therapy. J Hypertens 2015; 33:354-365.

35. Watanabe Y, Kikuchi T, Mitsuhashi T, Kimura H, Tsuchida Y, Otsuka K. Administration of angiotensin receptor II blockade improves vascular function, urinary albumin excretion, and left ventricular hypertrophy in low-risk essential hypertensive patients receiving antihypertensive treatment with calcium channel blockers. Clin Exp Hypertens 2013; 35:87-94.

36. Collin C, Briet M, Tran TC, Beaussier H, Benistan K, Bensalah M, et al. Long-term changes in arterial structure and function and left ventricular geometry after enzyme replacement therapy in patients affected with Fabry disease. Eur J Prev Cardiol 2012; 19:43-54.

37. Mizuguchi Y, Oishi Y, Miyoshi H, Iuchi A, Nagase N, Oki T. Telmisartan improves morphologic and functional changes in both left ventricular myocardium and carotid arterial wall in patients with hypertension: assessment by tissue Doppler imaging and carotid ultrasonography. Echocardiography 2010; 27:864-872.

38. Ruvolo A, Mercurio V, Fazio V, Carlomagno G, Russo T, Affuso F, et al. Efficacy and safety of valsartan plus hydroclorothiazide for high blood pressure. World J Cardiol 2010; 2:125-130.

39. Hashimoto J, Westerhof BE, Westerhof N, Imai Y, O'Rourke MF. Different role of wave reflection magnitude and timing on left ventricular mass reduction during antihypertensive treatment. $J$ Hypertens 2008; 26:1017-1024.
40. Hashimoto J, Imai Y, O'Rourke MF. Monitoring of antihypertensive therapy for reduction in left ventricular mass. Am J Hypertens 2007; 20:1229-1233.

41. Ikonomidis I, Mazarakis A, Papadopoulos C, Patsouras N, Kalfarentzos F, Lekakis J, et al. Weight loss after bariatric surgery improves aortic elastic properties and left ventricular function in individuals with morbid obesity: a 3-year follow-up study. J Hypertens 2007; 25:439-447.

42. Tomiyama H, Kimura Y, Sakuma Y, Matuno K, Yoshida H, Doba N. The effects of monotherapy or combined therapy with an angiotensin converting enzyme inhibitor following initial treatment with calcium channel blockers on residual cardiovascular abnormalities. Clin Exp Hypertens 2000; 22:493-506.

43. Spronck B, Avolio AP, Tan I, Butlin M, Reesink KD, Delhaas T. Arterial stiffness index beta and cardio-ankle vascular index inherently depend on blood pressure but can be readily corrected. J Hypertens 2017; 35:98-104.

44. Baksi AJ, Treibel TA, Davies JE, Hadjiloizou N, Foale RA, Parker KH, et al. A meta-analysis of the mechanism of blood pressure change with aging. J Am Coll Cardiol 2009; 54:2087-2092.

45. Huang C, Guo D, Lan F, Zhang H, Luo J. Noninvasive measurement of regional pulse wave velocity in human ascending aorta with ultrasound imaging: an in-vivo feasibility study. J Hypertens 2016; 34:2026-2037.

46. Dogui A, Kachenoura N, Frouin F, Lefort M, De Cesare A, Mousseaux E, et al. Consistency of aortic distensibility and pulse wave velocity estimates with respect to the Bramwell-Hill theoretical model: a cardiovascular magnetic resonance study. J Cardiovasc Magn Reson 2011; $13: 11$.

47. Willemet M, Vennin S, Alastruey J. Computational assessment of hemodynamics-based diagnostic tools using a database of virtual subjects: application to three case studies. J Biomech 2016; 49:39083914.

48. Chow B, Rabkin SW. Brachial-ankle pulse wave velocity is the only index of arterial stiffness that correlates with a mitral valve indices of diastolic dysfunction, but no index correlates with left atrial size. Cardiol Res Pract 2013; 2013:986847.

49. Sorof JM, Cardwell G, Franco K, Portman RJ. Ambulatory blood pressure and left ventricular mass index in hypertensive children. Hypertension 2002; 39:903-908. 